\title{
A pós-graduação na Universidade Federal da Fronteira Sul: interiorização e redução de assimetrias em uma região de fronteira
}

\section{The graduate study in the Federal University of the Southern Border: interiorization and reduction of inequality in a border region}

\section{Él posgrado en la Universidad Federal de Frontera Sur: interiorización y reducción de asimetrías en una región fronteriza}

Joviles Vitório Trevisol, doutor em Sociologia pela USP com pósdoutorado em Sociologia pelo CES/Universidade de Coimbra. Próreitor de Pesquisa e Pós-Graduação da Universidade Federal da Fronteira Sul,Chapecó, SC, Brasil. E-mail:joviles.trevisol@uffs.edu.br.

\section{Resumo}

A Universidade Federal da Fronteira Sul (UFFS) é uma das 18 universidades públicas federais criadas a partir de 2003 no Brasil. A criação da UFFS, numa região de fronteira, é parte e resultado de um processo singular, que pode ser considerado sui generis no conjunto das universidades públicas e no interior da própria história da educação superior brasileira. A UFFS incorpora o universo da fronteira (território, sociedade e cultura) em seu próprio nome, razão pela qual foi tomada como referência empírica para os propósitos deste artigo. Pretendese descrever a experiência de implantação da UFFS, com o intuito de compreender como uma universidade sediada numa região de fronteira se concebe e se relaciona com as temáticas e as problemáticas de seu entorno. A descrição e a análise se concentrarão, em especial, no processo de concepção e implantação da pós-graduação.

Palavras-chave: Educação Superior. Pós-Graduação. Região de Fronteira. UFFS. 


\section{Abstract}

The Federal University of the Southern Border is one of the 18 federal public universities created since 2003 in Brazil. The creation of UFFS, in a border region, is part and result of a unique process that can be considered sui generis among public universities and within of the history of Brazilian higher education. UFFS incorporates the notion of the border (territory, society and culture) in its own name, the reason why it was taken as empirical reference for the purposes of this article. This article intends to describe the implementation experience of the UFFS in order to understand how a university localized in the border region conceives itself and relates with the issues and problems of its surroundings. The description and analysis will focus in particular on the conception and the implementation of the graduate program.

Keywords: Higher Education. Graduate Program. Border Region. UFFS.

\section{Resumen}

La Universidad Federal del Sur de la Frontera es una de las 18 universidades públicas federales creadas a partir de 2003 en Brasil. La creación de UFFS, en una región fronteriza, es parte y consecuencia de un proceso único que se puede considerar sui generis en el conjunto de las universidades públicas y en el interior de la historia de la educación superior brasileña. UFFS incorpora el universo de la frontera (territorio, sociedad y cultura) en su propio nombre, por lo que vamos a tomar como referencia empírica de los propósitos del presente artículo. Se pretende describir la experiencia de implantación de la UFFS con el fin de entender cómo se concibe y se relaciona con las temáticas y problemas de su entorno. La descripción y el análisis se centrarán en particular en el proceso de concepción y en la implementación del posgrado.

Palabras clave: Educación Superior. Posgrado. Región Fronteriza. UFFS. 


\section{Introdução}

A educação superior no Brasil é tardia. O primeiro curso de nível superior (o Colégio Médico-Cirúrgico da Bahia) só passou a existir em março de 1808, em decorrência de um decreto de D. João VI assinado poucos dias após sua chegada ao Brasil. Similar ao que havia feito ao aportar nas terras da Bahia, o rei português criou, no mesmo ano, o segundo curso superior de Medicina, na cidade do Rio de Janeiro. Entre 1808 e 1821, período de permanência da Família Real no Brasil, foram criados sete cursos superiores (SAVIANI, 2004, 2007).

Diferentemente do que ocorreu em outros países europeus e, inclusive, nas colônias espanholas na América Latina (MUNIZ, 2006), o Brasil, nos seus primeiros 450 anos, empreendeu poucas iniciativas no sentido de instituir um vigoroso sistema de educação superior (FREITAG, 1980; SAMPAIO, 2000). As primeiras universidades foram criadas nos anos 20 do século passado. Na década seguinte, cabe destaque para a Universidade de São Paulo (1934). Nos anos 40 e seguintes, foram criadas inúmeras universidades públicas federais em vários estados da Federação: quatro na década de 40; seis na década de 50; 19 nos anos 60; quatro na década de 70; três nos anos 80; duas na década de 90 e 18 entre 2003 e 2014 (BITTAR, 2003; BRASIL, 2004; TREVISOL, 2015b).

Além das instituições de educação superior (IES) federais, surgiram centenas de instituições públicas estaduais, comunitárias e privadas. Entre 1920 e 2012, o número de IES passou de uma para 2.416, sendo 87,5\% particulares (2.112 IES) e 12,5\% públicas (304 IES) (BRASIL, 2014). O número de matrículas, por conseguinte, foi crescendo de forma exponencial. Em 1970, o Brasil tinha 300 mil estudantes de graduação; em 1980, eram 1.500.000; em 2000, 2.694.245; em 2004, 4.163.733; em 2012, 7.037.688 e, em 2013, 7.300.000 (BRASIL, 2006, 2014). Entre 1990 e 2012, foram criadas cerca de 6 milhões de novas matrículas de graduação. Entre 2003 e 2012, o crescimento foi correspondente a $81 \%$.

A pós-graduação brasileira, por conseguinte, é mais recente ainda. Até 1985, mais de 40\% dos doutores brasileiros tinham obtido seus doutorados em instituições estrangeiras. Na década de 90, apenas 
um em cada cinco títulos haviam sido obtidos no exterior (MARCHELLI, 2005). Em 1976, a título de ilustração, existiam 490 cursos de mestrado no Brasil e 183 de doutorado (CAPES, 2004). Atualmente, em 2015, são 3.815 mestrados (acadêmicos e profissionais) e 1.997 doutorados, com 77.067 docentes envolvidos (permanentes, colaboradores e visitantes) e 219.987 estudantes matriculados (CAPES, 2015).

O caráter tardio de nosso sistema de educação superior tem dimensões temporais e espaciais. Ele não pode ser compreendido apenas sob o prisma da temporalidade, pois as variáveis políticas, econômicas, sociais e culturais nacionais assumem especificidades de acordo com as características de cada região, compreendida esta como um conjunto de referências físicas (espaciais) e humanas (sociedade) que, em interação, produz um conjunto específico de condições de vida (SANTOS, 2010). A espacialidade, ao ser incorporada como dimensão de análise, revela, entre outros aspectos, que a expansão não se deu de forma simétrica em termos regionais. Os ritmos e as escalas variaram muito ao longo das décadas e lugares. Os primeiros cursos e IES concentraram-se na costa litorânea. O movimento em direção ao interior é bastante recente e assimétrico.

As desigualdades e as assimetrias regionais evidenciam-se mais claramente quando se toma como referência uma região em específico, como a Faixa de Fronteira, localizada na costa oeste do Brasil. As políticas públicas priorizaram a fronteira apenas quando a segurança nacional e os interesses de soberania estavam ameaçados. A educação superior foi relegada a um segundo plano. Apenas nos anos recentes a implantação de IES públicas foi inserida na agenda de desenvolvimento da região, integrando-se às políticas nacionais de expansão e de interiorização da graduação e da pós-graduação estabelecidas nos Planos Nacionais de Educação 2001-2010 e 2014-2024 e no Plano Nacional de PósGraduação 2011-2020.

O presente artigo descreve a experiência de uma universidade pública federal recentemente instituída (Lei n ${ }^{\circ}$ 12.029, de 15 de setembro de 2009), localizada numa região de fronteira próxima à Argentina, que decidiu conceber seu projeto político institucional e organizar a sua pós- 
graduação a partir dos grandes desafios que emergem de sua região de abrangência. Trata-se da Universidade Federal da Fronteira Sul (UFFS), uma IES multicampi situada nos três estados do Sul, que incorpora o universo da fronteira (território, sociedade e cultura) em seu próprio nome. Pretende este estudo, em síntese, apresentar a experiência de implantação da pós-graduação da UFFS com o intuito de explicitar como uma IES sediada numa região de fronteira se concebe e se relaciona com as problemáticas de seu entorno.

O artigo inicia contextualizando a fronteira no seu sentido mais amplo (Faixa de Fronteira) e no seu aspecto mais restrito (Mesorregião Grande Fronteira do Mercosul), procurando destacar os aspectos centrais dessa mesorregião. Em seguida, situa a criação da UFFS, seus principais compromissos institucionais e as diretrizes que orientam o processo de construção da pós-graduação. Por fim, procura enfatizar o papel que a UFFS vem cumprindo no esforço de reduzir as assimetrias da pósgraduação e as desigualdades socioeducacionais da região.

\section{A região da Faixa de Fronteira}

Do ponto de vista territorial, a Faixa de Fronteira é uma região que se estende do Norte ao Sul do país, totalizando 15.719 quilômetros de extensão e 150 quilômetros de largura, abrigando cerca de 10 milhões de habitantes de 11 estados brasileiros e correspondendo a aproximadamente $27 \%$ do território nacional e $5 \%$ da população brasileira (BRASIL, 2010, p. 17). Essa faixa diz respeito à costa oeste, em que o Brasil faz divisa com dez países da América do Sul: Uruguai, Argentina, Paraguai, Bolívia, Peru, Colômbia, Venezuela, Guiana, Suriname e Guiana Francesa. 


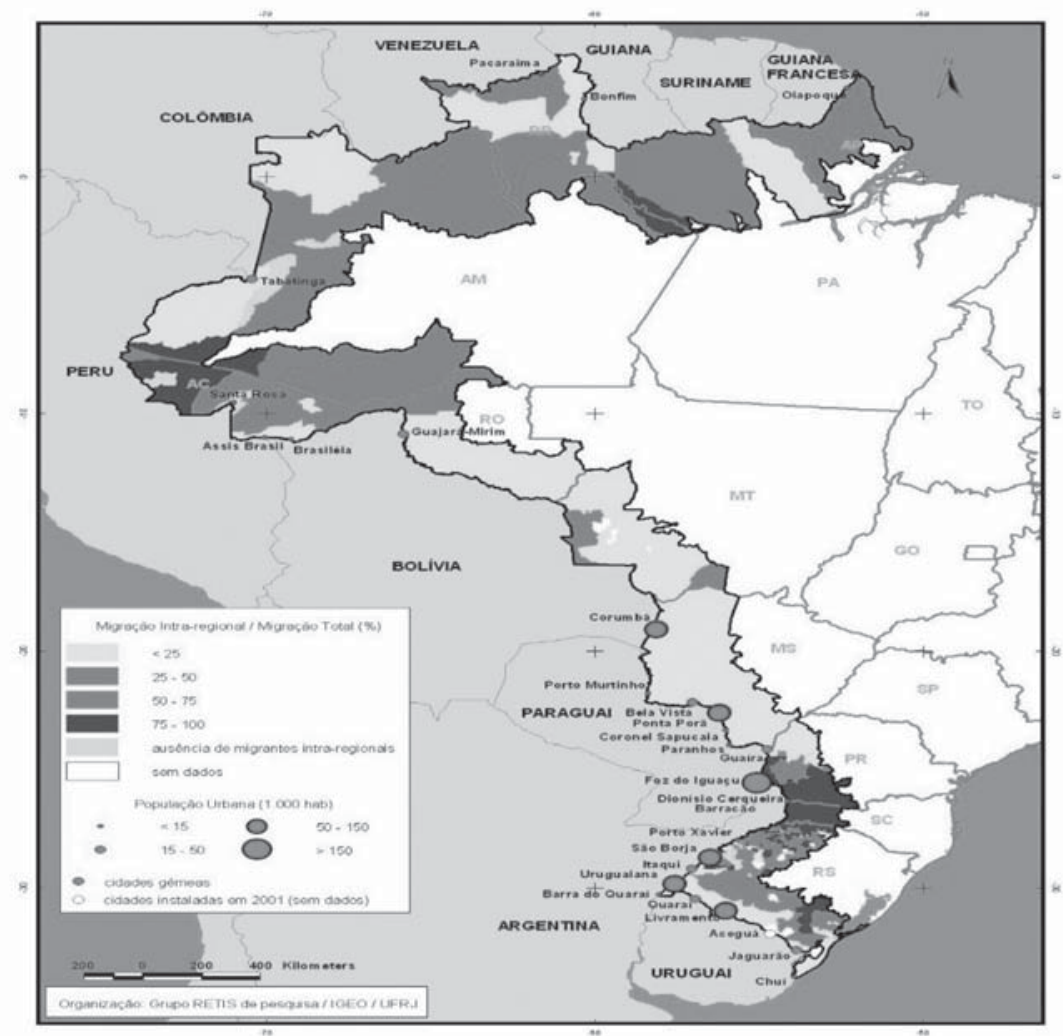

Fonte: Brasil (2010)

\section{Figura 1. Mapa da região da Faixa de Fronteira}

Por se tratar de área lindeira, a região foi palco de inúmeras disputas ao longo dos séculos, nas quais o Brasil recorreu às armas e às instâncias internacionais de arbitragem, a fim de demarcar as divisas, em algumas situações defendendo seu território, em outras, procurando ampliá-lo. Entre as disputas travadas, após o Tratado de Madri, cabe destacar a Guerra Guaranítica, a Guerra da Cisplatina, a Guerra do Paraguai, a Revolução Acriana e a Questão de Palmas. O Estado brasileiro, por essas e outras razões, designou a região como área de segurança nacional, conferindo-lhe um tratamento geopolítico e militar. De acordo com as fontes históricas disponíveis, D. Pedro Il foi o primeiro a estabelecer a faixa de fronteira, correspondendo, naquela ocasião, a 10 léguas ou 66 quilômetros de largura. Após algumas alterações, a Lei n 6.634 estabeleceu, em 2 de maio de 1979, a distância que prevalece até hoje (150 quilômetros) e definiu a região como "área indispensável 
à segurança nacional”. A Carta Magna de 1988 ratificou o conteúdo da lei nos seguintes termos:

“Art. 20, § 2 - A faixa de até cento e cinquenta quilômetros de largura, ao longo das fronteiras terrestres, designada como Faixa de Fronteira, é considerada fundamental para defesa do território nacional, e sua ocupação e utilização serão reguladas em lei.” (BRASIL, 1988).

\section{Quadro 1. Municípios, por estado, que integram a Faixa de Fronteira}

\begin{tabular}{|l|c|}
\hline Estado & Municípios \\
\hline Amapá & 8 \\
\hline Pará & 5 \\
\hline Roraima & 15 \\
\hline Amazonas & 21 \\
\hline Acre & 22 \\
\hline Rondônia & 27 \\
\hline Mato Grosso & 28 \\
\hline Mato Grosso do Sul & 44 \\
\hline Paraná & 139 \\
\hline Santa Catarina & 82 \\
\hline Rio Grande do Sul & 197 \\
\hline Total & $\mathbf{5 8 8}$ \\
\hline População & $\mathbf{1 0}$ milhões \\
\hline
\end{tabular}

Fonte: Ministério da Integração Nacional (BRASIL, 2010, p. 18).

A Faixa de Fronteira, por diversas razões, experimentou um relativo isolamento, que a colocou à margem das políticas centrais de desenvolvimento. 0 Estado brasileiro fez-se presente de maneira fraca e distante, exceto nos momentos em que julgou necessário intensificar sua presença militar, a fim de controlar os territórios e assegurar o controle legítimo da violência. Em vez de garantir e promover direitos sociais, ele se fez operante por meio da militarização do espaço.

\section{A Mesorregião Grande Fronteira do Mercosul}

A Mesorregião Grande Fronteira do Mercosul (Fronteira Sul) compreende 396 municípios, sendo 223 no norte do Rio Grande do Sul, 
131 no oeste de Santa Catarina e 42 no sudoeste do Paraná. Possui uma área total de 120.763 quilômetros quadrados e uma população estimada de 3.815.791 habitantes, dos quais cerca de 65\% vivem no campo (FÓRUM MESORREGIÃO GRANDE FRONTEIRA MERCOSUL, 2011).

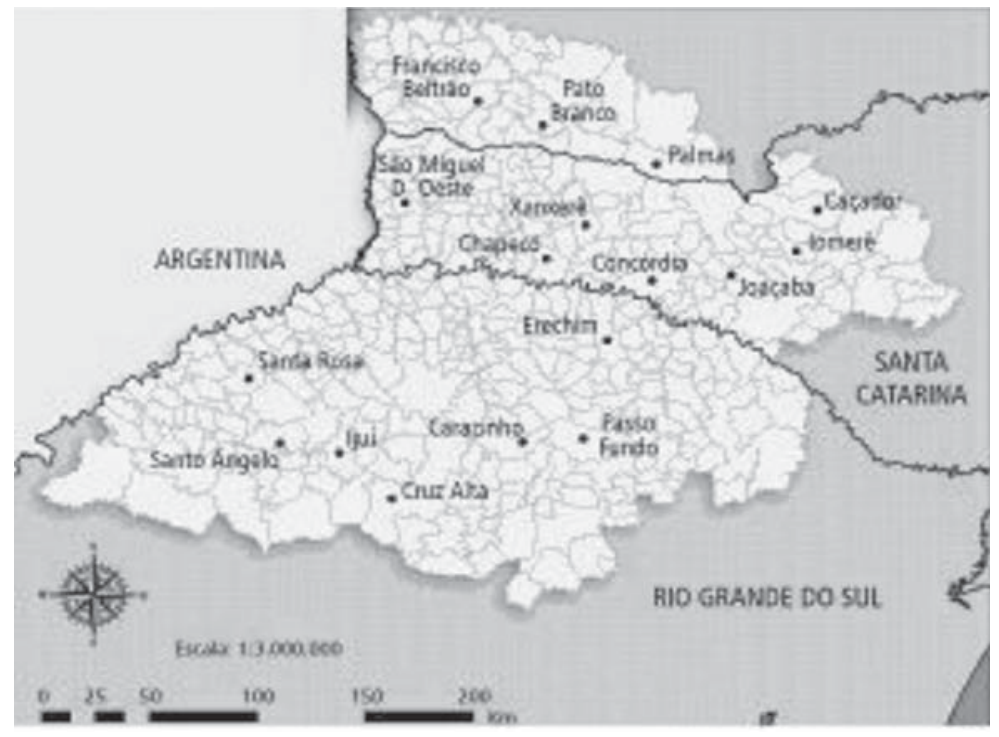

Fonte: Fórum Mesorregião Grande Fronteira Mercosul (2011).

\section{Figura 2. Mapa da Mesorregião Grande Fronteira do Mercosul}

Trata-se de uma região localizada entre 400 e 700 quilômetros das capitais dos três estados do Sul, tendo sido, ao longo dos séculos, palco de permanentes lutas pela posse da terra. No século XVIII, as disputas entre Portugal e Espanha pelo território acabaram por desencadear a Guerra Guaranítica e, com ela, um sangrento genocídio que dizimou milhares de indios guaranis que viviam em reduções autogestionadas no território das missões jesuíticas. No final do século XIX, a região foi objeto de nova disputa envolvendo os governos do Brasil e da Argentina. O litígio em questão envolveu a região oeste dos atuais estados do Paraná e de Santa Catarina. A Questão de Palmas, como ficou conhecida, foi submetida ao arbitramento do então presidente dos Estados Unidos, Grover Cleveland, que decidiu a favor do Brasil, estabelecendo que as fronteiras entre os dois países ocorreriam, a partir de 1895, pelos rios Peperi-Guaçu e Santo Antonio e não pelos rios Chapecó e Chopim (LOPES, 2002; HEINSFELD, 1996, 2007). No século XX, entre 1912 e 1916, nova disputa foi travada entre os estados do Paraná e Santa Catarina, resultando na Guerra do Contestado (MACHADO, 2004; VALENTINI, 2009). 
A luta pela terra prosseguiu e se aprofundou a partir dos anos 30 do século passado, com a chegada das companhias colonizadoras e, com elas, de descendentes de europeus (italianos, alemães e poloneses), que vieram em busca do sustento e da prosperidade. Índios, caboclos e colonos passaram a disputar cada palmo de chão, alguns defendendo a posse da terra como base da subsistência, outros lutando pela apropriação privada dos recursos naturais como forma de alavancar o desenvolvimento capitalista na região (RENK, 2000; RADIN, 2009). A comercialização dos lotes pelas colonizadoras, especialmente, no oeste de Santa Catarina e sudoeste do Paraná, foi atraindo milhares de famílias de colonos oriundas do vizinho estado do Rio Grande do Sul, dispostas a organizar uma pequena propriedade agrícola de base familiar.

Trata-se de uma região, como de resto todas as demais localizadas na Faixa de Fronteira, marcada pela precariedade de condições e pela escassez de recursos. A região ficou privada de investimentos em rodovias, ferrovias, aeroportos, estrutura de comunicação, saúde, habitação, assistência social e educação. A distância em relação aos grandes centros torna a vida mais precária, instável e difícil.

Os habitantes da fronteira sabem que raramente são prioridade. A instabilidade e a precariedade são dimensões fáticas do cotidiano, obrigando as pessoas a mobilizarem suas energias em diferentes formas de luta pela invenção de novas formas de sociabilidades e de soluções. Como sintetiza Boaventura de Sousa Santos (2002, p. 348):

\footnotetext{
Viver na fronteira significa ter de inventar tudo, ou quase tudo, incluindo o próprio ato de inventar. Viver na fronteira significa converter o mundo numa questão pessoal, assumir uma espécie de responsabilidade pessoal que cria uma transparência total entre os atos e as suas consequências. Na fronteira, vive-se da sensação de estar a participar da criação de um novo mundo.
}

As conquistas resultam, quase sempre, das lutas, da persistência e da capacidade de adaptação e de invenção. A vida na fronteira ensina que é preciso ser forte, lutador e persistente. Não viver dessa maneira implica sucumbir às precariedades e declinar da possibilidade de criação de um mundo melhor. As conquistas da fronteira, parafraseando Sousa 
Santos (2002, p. 351), decorrem da "prática da utopia e da utopia da prática."

\section{A educação superior na região Fronteira Sul}

A educação superior ilustra bem a fenomenologia da vida cotidiana descrita acima. A ausência de políticas de desenvolvimento para a região, especialmente a inexistência de investimentos voltados à interiorização das universidades públicas, foi fator que atuou decisivamente para o surgimento, a partir dos anos 50 do século passado, das primeiras IES comunitárias e dos primeiros cursos de graduação, a maioria ligada ao campo da formação de professores e das áreas do direito, administração e contabilidade.

Na região noroeste do Rio Grande do Sul, na cidade de Passo Fundo, foram criados, em 1950 e em 1956, respectivamente, a Sociedade Pró-Universidade de Passo Fundo (SPU) e o Consórcio Universitário Católico (CUC), que passaram a oferecer os primeiros cursos de graduação - Direito, Odontologia, Ciências Políticas e Economia, Belas Artes e Filosofia. Em 1967, a SPU e o CUC integraram-se, dando origem, no ano seguinte, à Universidade de Passo Fundo. Também, por iniciativa das lideranças comunitárias, a Ordem dos Frades Franciscanos (Capuchinhos) do Rio Grande do Sul e a comunidade de ljuí e região criaram, em 1956, a Faculdade de Filosofia, Ciências e Letras de ljuí (Fafi). Em 1969, o patrimônio da Fafi passou a integrar a Fundação de Integração, Desenvolvimento e Educação do Noroeste do Estado do Rio Grande do Sul (Fidene), que, em 1993, se transformou na Universidade de ljuí. Outras cidades do noroeste do Rio Grande do Sul, como Erechim, Cerro Largo, Frederico Westphalen, Santo Ângelo, Santiago e São Luiz Gonzaga criam, em 1992, a Universidade Regional Integrada do Alto Uruguai e das Missões (BITTAR, 1999; MACHADO, 2009; TREVISOL, 2015b).

Em Santa Catariana, na região oeste, os primeiros cursos de graduação (Administração, Pedagogia, Estudos Sociais, Ciências Contábeis e Direito) começaram a ser ofertados nos anos 70, com a 
criação das primeiras Fundações Educacionais de Educação Superior, uma modalidade institucional relativamente nova, pelo poder público municipal, porém de direito privado. A primeira a surgir foi a Fundação Universitária do Oeste Catarinense (Fuoc), em 1968, na cidade de Joaçaba. Em seguida, em 1971, vieram a Fundação de Ensino do Desenvolvimento do Oeste (Fundeste), em Chapecó; a Fundação Educacional e Empresarial do Alto Vale do Rio do Peixe (Femarp), em Videira; a Fundação Educacional do Alto Vale do Rio do Peixe (Fearpe), em Caçador, e a Fundação Educacional do Alto Uruguai Catarinense (Feauc), em Concórdia; em 1978, a Fundação Educacional do Extremo Oeste de Santa Catarina (Fenesc), em São Miguel do Oeste, e, em 1986, a Fundação Educacional dos Municípios do Alto Irani (Femai), em Xanxerê. Em pouco mais de duas décadas, essas pequenas e isoladas faculdades converteram-se em IES estruturadas, agregando centenas de professores e milhares de alunos. Em 1990, inicia-se o processo de transformação das fundações em universidades. Em 1996, o Ministério da Educação credenciou a Universidade do Oeste de Santa Catarina (Unoesc). No ano seguinte, o credenciamento foi conferido à Universidade do Contestado (UnC). Em 2002, surge a Universidade Comunitária Regional de Chapecó; em 2009, a Universidade Alto Vale do Rio do Peixe (Uniarp) e, no mesmo ano, também é criada a Universidade Federal da Fronteira Sul (PEGORARO, 2006, 2013; TREVISOL, 2009; MUNIZ, 2006).

Na região sudoeste do Paraná, a primeira instituição de educação superior foi instalada em 1967, na cidade de Palmas, com a criação do Centro Pastoral, Educacional e Assistencial Dom Carlos (Cpea), entidade mantenedora da Faculdade de Filosofia, Ciências e Letras (Fafi), regularizada em 1969. Em 1975, surgem mais duas IES na região: a Fundação Faculdade de Administração e Ciências Contábeis de Pato Branco (Facicon), com sede no município de Pato Branco (transformada em 1982 em Fundação de Educação Superior de Pato Branco) e a Faculdade de Ciências Humanas de Francisco Beltrão (Facibel) (BERNARTT, 2006). Em 1979, com sede no município de Palmas, é instituída a Faculdades Reunidas de Administração, Ciências Contábeis e Ciências Econômicas de Palmas (Facepal), a qual dá origem, em 2001, à Facipal, entidade que nasce da fusão das antigas Fafi e Facepal. Em 
1992, é criado, em Pato Branco, um campus do Cefet-PR, que passa a incorporar também a Fundação de Educação Superior de Pato Branco (Funesp). Em 1999, a Facibel foi incorporada à Universidade do Estado do Paraná (Unioeste). No ano de 2005, o Cefet - Unidade Pato Branco transforma-se em campus da Universidade Tecnológica Federal do Paraná (BERNARTT, 2006; TURMENA, 2011). Entre 1999 e 2001, são instaladas na região mais 10 IES, a maioria delas de natureza privada.

As IES comunitárias, como se pode observar, capitanearam o processo de interiorização dos cursos de graduação e de pós-graduação, sobretudo nos estados do Rio Grande do Sul e de Santa Catarina. De acordo com os dados recentes (junho 2015) disponíveis na Capes e nos sítios institucionais das IES da região em estudo, o setor comunitário responde por $100 \%$ dos cursos de doutorado e $87 \%$ dos cursos de mestrado ofertados no noroeste do Rio Grande do Sul e por 83\% dos cursos de mestrado no oeste de Santa Catarina (não há cursos de doutorado nessa região). No Paraná, diferentemente, os 10 cursos de doutorado e os 43 de mestrado, ofertados na região Sudoeste são de IES públicas estaduais.

\section{A criação da UFFS}

A implantação de uma universidade pública federal na região vinha sendo pautada há décadas por inúmeras organizações e lideranças. Os governos, de modo geral, responderam às demandas por meio de políticas voltadas ao apoio à criação de IES privadas (comunitárias e particulares) de educação superior. Nas décadas de 80 e 90, a despeito das pressões, a criação de novas universidades públicas federais não se firmou como pauta na agenda nacional. Em vez da expansão do sistema público federal, optou-se por intensificar a privatização, consolidando ainda mais o elitismo (SILVA JÚNIOR; SGUISSARDI, 2001; CHAUI, 1999; SOUSA SANTOS, 2005). De acordo com dados do Instituto Nacional de Pesquisas e Pesquisas Educacionais Anísio Teixeira (Inep) referentes ao ano de $2014,87,5 \%$ das IES brasileiras são privadas, respondendo por 73\% das matrículas de graduação no país (BRASIL, 2014). 
O ambiente político em relação à criação de novas universidades públicas federais alterou-se sensivelmente no início dos anos 2000, com a aprovação do Plano Nacional de Educação (PNE 2001-2010) e com a vitória eleitoral do então presidente Luiz Inácio Lula da Silva. O PNE 2001-2010 incorporou metas alvissareiras quanto à expansão das matrículas de graduação: ampliação de $12 \%$ para $30 \%$ do percentual de matrículas de educação superior para jovens entre 18 e 24 anos e oferta de, no mínimo, 40\% das matrículas pelo setor público (BRASIL, 2001).

A vitória de Luiz Inácio Lula da Silva nas eleições presidenciais de 2002 produziu mudanças importantes no campo das políticas educacionais. A expansão e a interiorização das vagas do sistema público passaram a ser promovidas por meio de inúmeros programas e ações, entre os quais o Programa de Apoio a Planos de Reestruturação e Expansão das Universidades Federais (Reuni), o Programa Universidade para Todos (Prouni), a criação de novas universidades federais e a Rede Federal de Educação Profissional, Científica e Tecnológica.

As políticas de expansão da rede de educação superior pública federal, sinalizadas pelo governo Lula logo no início de sua gestão, foram decisivas para a retomada e para o fortalecimento dos movimentos e das mobilizações em prol de uma universidade federal na fronteira sul. Além do favorável ambiente político, em 2003 o governo federal já aventava a criação da Universidade do Mercosul, uma IES com sede na região Sul, voltada para os temas da integração com os paísesmembros do Tratado. 0 momento era favorável e exigia uma atuação política mais intensa e coordenada.

Em outubro de 2003, antes de completar o seu primeiro ano de mandato, o presidente Luiz Inácio Lula da Silva confirmou sua visita à cidade de Chapecó (SC), por ocasião da abertura da Exposição-Feira Agropecuária, Industrial e Comercial de Chapecó (Efapi). A presença do então presidente desencadeou ampla mobilização por parte das lideranças políticas e dos movimentos sociais. As articulações realizadas na véspera renderam uma manifestação pública de Lula, 
proferida no discurso de abertura: "O oeste de Santa Catarina terá uma universidade federal". O aceno foi interpretado como uma importante vitória na luta pelo convencimento público, pois a antiga e restrita pauta passava a ser atual. O anúncio trouxe ânimo.

As reuniões de trabalho e as articulações foram intensificadas a partir de outubro de 2003, dando origem, em 2005, ao Movimento Pró-Universidade Federal (MPUF) coletivo de atores sociais e políticos, composto pelo Fórum da Mesorregião Grande Fronteira do Mercosul, movimentos sociais - especialmente a Federação dos Trabalhadores na Agricultura Familiar da Região Sul (Fetraf-Sul) e o Movimento dos Trabalhadores Rurais Sem Terra (MST) -, universidades, setores da igreja católica, movimento estudantil, sindicatos, associações de municípios, lideranças políticas (vereadores, prefeitos, deputados, senadores) e imprensa.

A atuação do Movimento Pró-Universidade Federal passou a ocorrer em várias frentes, cabendo destacar a forte mobilização social e a participação política de movimentos sociais e outras organizações da sociedade civil, articulação política, atuação parlamentar, grupos de trabalho, reuniões com o Ministério da Educação, divulgação na imprensa etc.

Em 2005, o então deputado federal Cláudio Vignatti apresentou à Câmara dos Deputados o Projeto de Lei n 6.037/2005, propondo a criação de uma universidade para a Mesorregião Grande Fronteira do Mercosul. No ano seguinte, em 2006, a Universidade Federal de Santa Catarina (UFSC) foi solicitada a coordenar um grupo de trabalho responsável pela elaboração do primeiro projeto acadêmico da futura universidade.

As articulações foram intensificadas em 2007. No dia 24 de agosto foram organizadas manifestações de apoio ao projeto em mais de 15 cidades dos três estados do Sul, reunindo milhares de pessoas. Em outubro, após inúmeras reuniões de trabalho com representantes do Movimento Pró-Universidade, o então ministro da Educação, Fernando 
Haddad, anunciou, em audiência pública, o compromisso do governo com a criação da universidade federal. Em 26 de novembro o MEC publicou a Portaria n 948/2007, instituindo a comissão responsável pela elaboração do projeto, composta por integrantes de movimentos sociais, técnicos do MEC e representantes da Universidade Federal de Santa Maria e da Universidade Federal de Santa Catarina. Finalmente, no dia 12 de dezembro, o ministro anunciou a criação da Universidade Federal da Mesorregião da Grande Fronteira do Mercosul, em solenidade de assinaturas de atos complementares ao Plano Nacional de Desenvolvimento da Educação, no Palácio do Planalto. O anúncio do ministro, aguardado com muita expectativa pelo Movimento PróUniversidade Federal, formalizou a inclusão da UFFS no programa de expansão das IES públicas federais.

A declaração apresentou desafios novos, entre os quais os trâmites institucionais do projeto perante as instâncias do Poder Executivo e do Congresso Nacional. Importante passo nessa direção foi dado em 16 de julho de 2008, quando o então presidente da República assinou o projeto de lei (PL) que propunha a criação da UFFS, remetendo-o para o Congresso Nacional. Em 12 de novembro, o PL nº 3774/08 foi aprovado pela Comissão de Trabalho, de Administração e Serviço Público. No ano seguinte, em 20 de maio de 2009, a Comissão de Finanças e Tributação da Câmara dos Deputados também aprovou o PL. No mês seguinte, em 17 de junho, a Comissão de Constituição e Justiça e de Cidadania da Câmara dos Deputados emitiu parecer favorável à proposta. O PL, em seguida, tramitou nas Comissões de Justiça e de Educação do Senado Federal, recebendo aprovação em 18 e 25 de agosto, respectivamente. Em 15 de setembro de 2009, finalmente, a lei de criação da UFFS (Lei $n^{\circ}$ 12.029/09) foi sancionada pelo então presidente da República, assumindo desde então as características de uma universidade multicampie interestadual, com presença, conforme destaca a Figura 3, nos três estados da região Sul. 


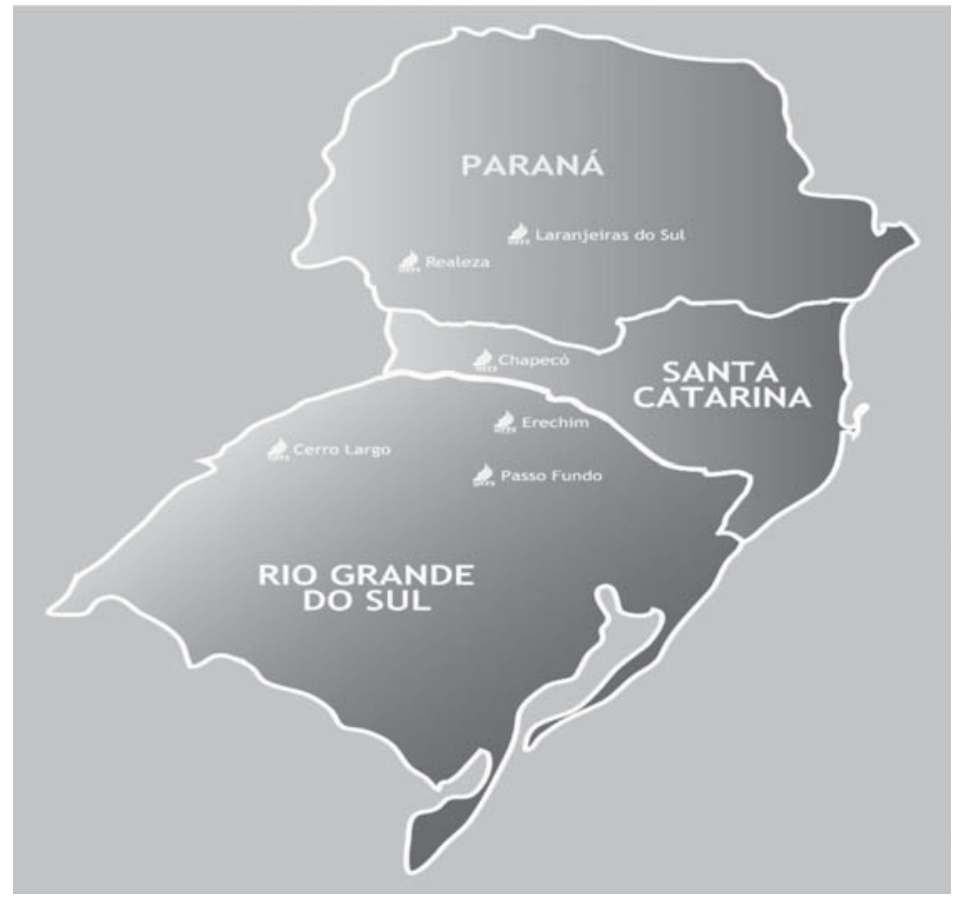

Fonte: Diretoria de Comunicação/UFFS, 2014

\section{Figura 3. Presença da UFFS em sua região de abrangência}

A UFFS é parte e resultado de um processo singular, que pode ser considerado suigeneris no conjunto das IES públicas e no interior da própria história da educação superior brasileira (TREVISOL; CORDEIRO; HASS, 2011). Ela surgiu dos processos de participação social e política, nos quais as organizações da sociedade civil, os movimentos sociais e as lideranças políticas e comunitárias tiveram atuação decisiva. Longe de ser algo irrelevante, a mobilização social atuou decisivamente sobre a construção da identidade e a definição dos princípios, diretrizes e políticas que integram o projeto político institucional (UFFS, 2009).

O desenho institucional da UFFS foi definido a partir de um diálogo interativo entre estado e sociedade civil, entre MEC e movimentos sociais e organizações comunitárias, entre quem produz conhecimento científico e quem se apropria dele. As prioridades, especialmente os primeiros cursos de graduação e pós-graduação, foram estabelecidas com base em uma análise detalhada das características (demográficas, econômicas, culturais e socioeducacionais) e nas históricas lacunas presentes na região. 


\section{A UFFS e a pós-graduação na fronteira}

Como destacado, as distâncias em relação aos grandes centros do país e a histórica inexistência de políticas de desenvolvimento para as regiões de fronteira têm gerado e reproduzido desigualdades e assimetrias. Os estudos e os debates sobre as dinâmicas de desenvolvimento da mesorregião foram explicitando os principais compromissos que a instituição deveria assumir, materializando-os nas políticas de graduação, pós-graduação, pesquisa e extensão.

Na fase inicial de implantação foram firmados cinco grandes compromissos institucionais, traduzidos em grandes áreas de atuação:

\section{a) Educação básica e formação de professores}

Numa região de fronteira, com baixa presença de IES públicas, a oferta de ensino, pesquisa e extensão no campo da formação de professores foi considerada estratégica. A UFFS incorporou em seu projeto institucional as políticas nacionais estabelecidas nos Planos Nacionais de Educação 2001-2010 e 2014-2024 e na Política Nacional de Formação de Professores (Decreto $n^{\circ}$ 6.755/09), decidindo pela oferta de inúmeros cursos de graduação (licenciatura) em todos os campi, pós-graduação, pesquisa e extensão. Na região, como de resto em todo o país, o percentual de professores com licenciatura na área em que atua é bastante baixo. A título de ilustração, apenas 16\% dos professores de Física que atuam nos anos finais do ensino fundamental e no ensino médio possuem formação em Física. Na área de Português, esse percentual é de 54\% (GATTI, 2014).

\section{b) Agricultura familiar e agroecologia}

No Brasil a agricultura familiar gera a maioria dos empregos do campo e responde por 70\% dos alimentos que vão à mesa dos brasileiros. Na região Fronteira Sul, mais de $85 \%$ das propriedades rurais se definem como de agricultura familiar. A despeito do processo de urbanização, o setor continua sendo o principal dinamizador da economia da maior parte dos municípios e dos estados do Sul. Tendo isso presente, a UFFS firmou 
compromisso com a formação acadêmica, a produção de conhecimentos, tecnologias e práticas sustentáveis, que potencializam a agricultura familiar, a produção de alimentos saudáveis e a sustentabilidade.

\section{c) Energias renováveis e sustentabilidade}

As temáticas ambientais foram incorporadas ao projeto institucional por serem centrais ao desenvolvimento regional e à sustentabilidade do planeta. Entre as inúmeras problemáticas ambientais, decidiu-se dar maior ênfase aos seguintes temas: energias renováveis, resíduos sólidos, uso racional e sustentável dos recursos hídricos e gestão integrada de bacias hidrográficas.

\section{d) Saúde}

O compromisso institucional com a saúde vem sendo fortemente demandado pela comunidade regional. As dificuldades para atrair e fixar mestres e doutores e, aliado a isso, os elevados investimentos exigidos para a implantação de cursos na área têm historicamente limitado a oferta de cursos no campo da saúde na região. Tendo em vista a forte demanda oriunda do setor público, a UFFS decidiu implantar cursos que formem profissionais em condições de atuar no Sistema Único de Saúde, nos programas Saúde da Família e Comunidade e nas instituições responsáveis para gestão dos serviços de saúde.

\section{e) Gestão}

O associativismo civil e o cooperativismo têm presença marcante na organização social, política e econômica da região. As cooperativas, as associações de produtores e a economia solidária respondem por fatias importantes da economia regional. Em vez dos tradicionais cursos de Administração de Empresas, foram priorizados cursos voltados à formação de gestores de micro e pequenas empresas, cooperativas, organizações econômicas populares, agricultura familiar etc.

Conforme se pode observar no Quadro 2, as áreas estratégicas de atuação foram tomadas como referência para a definição e a implantação dos primeiros cursos de graduação e de pós-graduação. 
Quadro 2. A organização da graduação e da pós-graduação, segundo as áreas de atuação

\begin{tabular}{|c|c|c|c|}
\hline Áreas & Graduação ${ }^{1}$ & $\begin{array}{l}\text { Pós-graduação } \\
\text { lato sensu }\end{array}$ & $\begin{array}{l}\text { Pós-graduação } \\
\text { stricto sensu }\end{array}$ \\
\hline $\begin{array}{l}\text { Educação básica } \\
\text { e formação de } \\
\text { professores }^{2}\end{array}$ & $\begin{array}{l}\text { - Ciências } \\
\text { Biológicas ( } 2 \\
\text { cursos) } \\
\text { - Ciências Sociais } \\
\text { (2 cursos) } \\
\text { - Educação do } \\
\text { Campo (3 cursos) } \\
\text { - Física (2 cursos) } \\
\text { - Filosofia (2 } \\
\text { cursos) } \\
\text { - Geografia (2 } \\
\text { cursos) } \\
\text { - História (2 } \\
\text { cursos) } \\
\text { - Letras (3 cursos) } \\
\text { - Matemática } \\
\text { - Pedagogia (2 } \\
\text { cursos) } \\
\text { - Química (2 } \\
\text { cursos) }\end{array}$ & $\begin{array}{l}\text { - Educação Integral (3 } \\
\text { cursos) } \\
\text { - Ensino de Ciências e } \\
\text { Matemática } \\
\text { - Ensino de Língua e } \\
\text { Literatura } \\
\text { - Epistemologia e } \\
\text { Metafísica } \\
\text { - História da Ciência } \\
\text { - História Regional } \\
\text { - Interdisciplinaridade } \\
\text { e Práticas } \\
\text { Pedagógicas } \\
\text { - Linguagem e Ensino } \\
\text { - Literaturas do Cone } \\
\text { Sul } \\
\text { - Orientação } \\
\text { Educacional } \\
\text { - Processos } \\
\text { Pedagógicos na } \\
\text { Educação Básica } \\
\text { - Teorias Linguísticas } \\
\text { Contemporâneas }\end{array}$ & $\begin{array}{l}\text { - PPG em } \\
\text { Educação } \\
\text { (Acadêmico) } \\
\text { - PPG em } \\
\text { Educação } \\
\text { (Profissional) } \\
\text { - PPG em Estudos } \\
\text { Linguísticos } \\
\text { - PPG } \\
\text { Interdisciplinar } \\
\text { em Ciências } \\
\text { Humanas } \\
\text { - PPG em } \\
\text { Matemática } \\
\text { (Profmat) }\end{array}$ \\
\hline $\begin{array}{l}\text { Agricultura } \\
\text { familiar e } \\
\text { agroecologia }\end{array}$ & $\begin{array}{l}\text { - Agronomia (4 } \\
\text { cursos) } \\
\text { - Engenharia de } \\
\text { Aquicultura } \\
\text { - Engenharia de } \\
\text { Alimentos }\end{array}$ & $\begin{array}{l}\text { - Desenvolvimento } \\
\text { Rural Sustentável e } \\
\text { Agricultura Familiar } \\
\text { - Produção de Leite } \\
\text { Agroecológico }\end{array}$ & $\begin{array}{l}\text { - PPG em } \\
\text { Agroecologia e } \\
\text { Desenvolvimento } \\
\text { Rural Sustentável }\end{array}$ \\
\hline Áreas & Graduação $^{3}$ & $\begin{array}{c}\text { Pós-graduação } \\
\text { lato sensu }\end{array}$ & $\begin{array}{l}\text { Pós-graduação } \\
\text { stricto sensu }\end{array}$ \\
\hline $\begin{array}{l}\text { Energias } \\
\text { renováveis e } \\
\text { sustentabilidade } \\
\end{array}$ & $\begin{array}{l}\text { - Engenharia } \\
\text { Ambiental (3 } \\
\text { cursos) }\end{array}$ & Em construção & $\begin{array}{l}\text { - PPG em Ciência } \\
\text { e Tecnologia } \\
\text { Ambiental }\end{array}$ \\
\hline Saúde & $\begin{array}{l}\text { - Enfermagem } \\
\text { - Medicina (2 } \\
\text { cursos) } \\
\text { - Nutrição } \\
\text { - Medicina } \\
\text { Veterinária }\end{array}$ & $\begin{array}{l}\text { - Saúde Coletiva } \\
\text { - Segurança } \\
\text { Alimentar e } \\
\text { Nutricional }\end{array}$ & Em construção \\
\hline Gestão & $\begin{array}{l}\text { - Administração (2 } \\
\text { cursos) } \\
\text { - Ciências } \\
\text { Econômicas }\end{array}$ & Em construção & $\begin{array}{l}\text { - PPG } \\
\text { Interdisciplinar } \\
\text { em } \\
\text { Desenvolvimento } \\
\text { e Políticas } \\
\text { Públicas }\end{array}$ \\
\hline
\end{tabular}

Fonte: DRA/PROGRAD/UFFS, 2015; DPG/PROPEPG/UFFS/2015.
1 Apenas dois cursos de graduação da UFFS (Arquitetura e Urbanismo e Ciência da Computação) não aparecem no quadro, tendo em vista o fato de não terem relação estreita com as áreas especificadas. 2 Todos os cursos de graduação ofertados pela UFFS no campo da formação de professores são licenciaturas.

3 Apenas dois cursos de graduação da UFFS (Arquitetura e Urbanismo e Ciência da Computação) não aparecem no quadro, tendo em vista o fato de não terem relação estreita com as áreas especificadas. 
A pós-graduação na UFFS passou a ser estruturada a partir de um conjunto de estudos e debates sobre as desigualdades, as assimetrias e as necessidades da região, envolvendo a comunidade acadêmica e regional. A primeira iniciativa fundamental nessa direção foi realizada entre junho e setembro de 2010, poucos meses após o início do processo de implantação da universidade. A / Conferência de Ensino, Pesquisa e Extensão (COEPE): Construindo agendas e definindo rumos, como ficou conhecida, envolveu cerca de 4 mil pessoas dos três estados que integram a região de abrangência, cabendo destacar a significativa presença dos docentes, servidores técnico-administrativos e estudantes da UFFS, professores da educação básica, docentes de outras instituições de educação superior, lideranças políticas, organizações comunitárias e empresariais, sindicatos, cooperativas populares, movimentos sociais, ONGs e lideranças das comunidades indígenas. O documento final da COEPE (UFFS, 2011) definiu as políticas norteadoras da pós-graduação, assim como os programas e os cursos a serem implantados nos primeiros cinco anos de existência da universidade.

As discussões realizadas na I COEPE impulsionaram uma série de ações, algumas de caráter mais estratégico, outras de natureza mais prática. Entre as ações estratégicas, cabe destacar (i) a elaboração e a aprovação das principais normativas institucionais que regulamentam a pós-graduação (Res. n 2/2012-CONSUNI/ CPPG; Res. $n^{\circ}$ 7/2013-CONSUNI/CPPG; Res. n 2/2013-CONSUNI/ CPPG; Res. Conjunta $n^{\circ}$ 1/2014-CONSUNI/CGRAD/CPPG e Res. $n^{\circ}$ 3/2014-CONSUNI/CPPG) e (ii) o estudo sobre as características e as assimetrias da pós-graduação no Sul do Brasil, particularmente, na Mesorregião Grande Fronteira do Mercosul.

O diagnóstico sobre a pós-graduação regional auxiliou na definição dos cursos e programas a serem implantados. Em outubro de 2010, foram instituídos os primeiros grupos de trabalho responsáveis pela elaboração das propostas a serem submetidas à Capes. A primeira submissão ocorreu em 2011, resultando na aprovação do Programa de Pós-Graduação em Estudos Linguísticos (PPGEL). No ano seguinte, foi recomendado o mestrado em Educação (PPGE) e, em 2013, o mestrado em Agroecologia e Desenvolvimento Rural Sustentável (PPGADRS) e o mestrado em Ciência e Tecnologia Ambiental (PPGCTA). Em 2014, foram 
aprovados o mestrado interdisciplinar em Ciências Humanas (PPGICH), o mestrado profissional em Educação (PPGPE) e a adesão da UFFS ao mestrado profissional em Matemática (Profmat). No início de 2015, foi recomendado o Programa de Pós-Graduação em Desenvolvimento e Políticas Públicas (PPGDPP).

Em seus primeiros cinco anos de existência, a UFFS implantou oito programas de pós-graduação, nível mestrado, sendo seis acadêmicos e dois profissionais. A demanda pelas vagas ofertadas tem sido bastante expressiva, conforme mostram os dados referentes aos editais de ingresso de 2015, constantes no Quadro 3.

Quadro 3. Relação candidato/vaga nos cursos de PG da UFFS, ingresso 2015

\begin{tabular}{|l|c|c|c|}
\hline \multicolumn{1}{|c|}{ Programas } & $\begin{array}{c}\text { N }{ }^{\circ} \text { de } \\
\text { inscritos }\end{array}$ & $\begin{array}{c}\text { N }{ }^{\circ} \text { de } \\
\text { vagas }\end{array}$ & $\begin{array}{c}\text { Relação } \\
\text { candidato/ } \\
\text { vaga (\%) }\end{array}$ \\
\hline PPG em Estudos Linguísticos & 39 & 20 & 1,95 \\
\hline PPG em Educação & 238 & 20 & 11,90 \\
\hline PPG em Agroecologia e Des. Rural Sustentável & 61 & 20 & 3,05 \\
\hline PPG em Ciência e Tecnologia Ambiental & 97 & 20 & 4,95 \\
\hline PPG Profissional em Matemática & 176 & 15 & 11,73 \\
\hline PPG Profissional em Educação & 208 & 20 & 10,4 \\
\hline PPG Interdisciplinar em Ciências Humanas & 157 & 20 & 7,85 \\
\hline PPG em Desenvolvimento e Políticas Públicas & 240 & 15 & 16,00 \\
\hline TOTAL & $\mathbf{1 . 2 1 6}$ & $\mathbf{1 5 0}$ & $\mathbf{8 . 1 0}$ \\
\hline
\end{tabular}

Fonte: DPG/PROPEPG/UFFS/2015.

Outro aspecto importante a ser destacado é o baixo percentual de evasão na pós-graduação. A média de desistentes, considerando o total dos ingressantes em cada ano, é de 1,62\%.

Interiorização da pós-graduação e redução de assimetrias

A UFFS vem ampliando a presença da educação superior gratuita numa região historicamente excluída das políticas públicas de 
educação superior. Assim como a graduação, a pós-graduação é tardia e concentrada nas IES comunitárias. Os primeiros cursos de mestrado na região datam do final da década de 90 e os de doutorado só foram implantados na última década. De acordo com os dados disponíveis no GeoCapes (CAPES, 2015) e nos sítios das 11 IES da região que têm programas de pós-graduação, são ofertados, atualmente (junho de 2015) 91 mestrados e 17 doutorados.

Os cursos de mestrado são, na sua grande maioria (81\%), conceito 3. Apenas um, de um total de 91 cursos, dispõe de conceito 5. Os programas são ofertados, majoritariamente, por IES comunitárias no noroeste do Rio Grande do Sul (87\%) e no oeste de Santa Catarina (83\%). No sudoeste do Paraná, 100\% dos mestrados são oferecidos pelas IES públicas, sendo 32 cursos pela Unioeste e oito pela UTFPR.

Quanto aos doutorados, 95\% deles, de um total de 17, dispõem de conceito 4. Apenas um programa apresenta nota 5. Quanto à natureza jurídica das IES ofertantes, as universidades comunitárias respondem por $100 \%$ dos doutorados no noroeste do Rio Grande do Sul. No Paraná há predomínio absoluto das IES públicas. No oeste de Santa Catarina não há, até o momento, oferta de cursos próprios de doutorado pelas IES da região.

Os dados revelam assimetrias que precisam ser enfrentadas. Alguns desafios revestem-se de particular importância para a UFFS e para as IES que atuam na região. Entre os mais importantes, cabe destacar (i) a necessidade do aumento do número de doutorados na região; (ii) o aumento da presença da pós-graduação pública e gratuita; (iii) a qualificação dos cursos existentes, com elevação das notas da avaliação; (iv) a inserção dos temas da fronteira nas linhas de pesquisa dos programas e (v) a fixação de doutores na região.

\section{Considerações finais}

O processo institucional descrito neste artigo é bastante recente, razão pelo qual ainda não há indicadores suficientes que permitam 
avaliar os impactos da presença da pós-graduação da UFFS na sua região de abrangência. Trata-se de uma IES pública federal em construção, sediada numa região que integra a Faixa de Fronteira, com seis anos de existência e que assumiu o desafio de construir seu projeto político institucional a partir dos desafios que caracterizam a região de sua abrangência.

A despeito das dificuldades típicas de uma IES localizada no interior do país, a UFFS tem procurado ser inovadora em sua proposta acadêmica e na forma como se relaciona com as problemáticas locais / globais. Por meio da pós-graduação, a instituição procura desenvolver formação acadêmica de alto nível, assim como promover a ciência, a tecnologia e a inovação na condição de bens públicos a serviço da sociedade. Orientada por essa concepção, a UFFS procura relacionarse com a sociedade de forma dialógica e interativa e não unilateral e distante. Em vez de adotar a postura de uma instituição hierarquicamente superior à comunidade onde está inserida (universidade-fortaleza), ela visa ampliar as zonas de contato e intensificar a interatividade, a inserção e as relações de cooperação (universidade-rede). Afinal, quanto mais a universidade se insere na comunidade, tanto mais esta se insere na universidade (SOUSA SANTOS, 2005).

A experiência da UFFS, resguardadas as devidas proporções, reflete o movimento que as pessoas - e suas instituições - que vivem na fronteira são obrigadas a fazer cotidianamente. Na fronteira, parafraseando Boaventura de Sousa Santos (2002, p. 351), vive-se a sensação de estar criando um novo mundo. Os povos da fronteira são desafiados a inventar tudo. A educação superior, assim como todas as conquistas da fronteira, também decorre da "prática da utopia e da utopia da prática".

Recebido em 20/07/2015 Aprovado em 08/09/2015 


\section{Referências}

BERNARTT, M. de L. Desenvolvimento e educação superior: um estudo do sudoeste do Paraná nos últimos cinquenta anos. 2006. Tese (Doutorado em Educação)- Universidade de Campinas, São Paulo, 2006.

BITTAR, M. Universidade comunitária: uma identidade em construção. 1999. 249 p. (Doutorado em Educação)- Universidade Federal de São Carlos, São Carlos, 1999. Disponível em:<http:/ / www.comunitarias.org. br/docs/teses/mariluce_bittar.pdf>. Acesso em: 10 jun. 2015.

O ensino superior privado no Brasil e a formação do segmento das universidades comunitárias. 2003. Disponivel em: <http://168.96.200.17/ar/libros/anped/1108T.PDF>. Acesso em: 10 jun. 2015.

BRASIL. Lei n 10.172, de 09 de janeiro de 2001. Aprova o Plano Nacional de Educação e dá outras providências. Diário Oficial [da] República Federativa do Brasil, Poder Executivo, Brasília, DF, 10 de jan. 2001. Seção 1, p. 1.

. Lei $n^{\circ}$ 12.029, de 15 de setembro de 2009. Lei de criação da UFFS. Diário Oficial [da] República Federativa do Brasil, Poder Executivo, Brasília, DF, 16 de set. 2009. Seção 1, p.1.

Lei $n^{\circ}$ 13.005, de 25 de junho de 2014. Aprova o Plano Nacional de Educação e dá outras providências. Diário Oficial [da] República Federativa do Brasil, Poder Executivo, Brasília, DF, 26 de jun. 2014. Seção 1, Edição Extra, p. 1.

Lei $n^{\circ}$ 6.634/79. Dispõe sobre a Faixa de Fronteira. Diário Oficial [da] República Federativa do Brasil, Poder Executivo, Brasília, DF, 3 de maio 1979. Seção 1, p. 1.

CAPES - Coordenação de Aperfeiçoamento de Pessoal de Nivel Superior. Plano Nacional de Pós-Graduação 2005-2010. Brasília, DF: Capes, 2004. Disponível em: <www.capes.gov.br>. Acesso em: 10 jun. 2015. 
Plano Nacional de Pós-Graduação 2011-2020. Brasília, DF:

Capes, 2010. v. 1. 309 p. Disponivel em: <www.capes.gov.br>. Acesso em: 10 jun. 2015.

Ferramenta de dados georreferencial (GeoCapes). Disponível em: <www.capes.gov.br>. Acesso em: 10 jun. 2015.

CHAUİ, M. Ideologia neoliberal e universidade. In: OLIVEIRA, F.; PAOLI, M. C. (Org.). Os sentidos da democracia. Petrópolis: Vozes, 1999.

FÓRUM MESORREGIÃO GRANDE FRONTEIRA MERCOSUL. Plano de Desenvolvimento Integrado Sustentável da Mesorregião Grande Fronteira do Mercosul. 2011. Disponível em: <http://mesomercosul. org.br/downloads.asp>. Acesso em: 10 jun. 2015.

FREITAG, B. Escola, estado e sociedade. São Paulo: Moraes, 1980.

GATTI, B. Formação inicial de professores para a educação básica: pesquisas e políticas educacionais. Revista Estudos de Avaliação Educacional, São Paulo, v. 35, n. 57, p. 24-54, jan./abr. 2014.

HEINSFELD, A. Fronteira Brasil/Argentina: a questão de Palmas (de Alexandre de Gusmão a Rio Branco). Passo Fundo: Méritos, 2007.

A questão de Palmas entre Brasil e Argentina e o início da colonização alemã no baixo vale do Rio do Peixe-SC. Joaçaba: Ed. Unoesc, 1996.

INEP - Instituto Nacional de Estudos e Pesquisas Educacionais Anísio Teixeira. Censo da Educação Superior. Disponível em: <http://portal. inep.gov.br/web/censo-da-educacao-superior>. Acesso em: 1 jul. 2014.

Evolução Ensino Superior. Graduação 1980-1998. Disponível em: <www.inep.gov.br>. Acesso em: 8 nov. 2004

. Educação Superior Brasileira 1991-2004: Santa Catarina. Brasília: Inep, 2006. 
LOPES, S. O Território do Iguaçu no contexto da "Marcha para o Oeste". Cascavel: Edunioeste, 2002.

MARCHELLI, P. S. Formação de doutores no Brasil e no mundo: algumas comparações. RBPG, Brasília, DF, v. 2, n. 3, p. 7-29, mar. 2005.

MACHADO, P. P. Lideranças do Contestado: a formação e a atuação das chefias caboclas. 1912-1916. Campinas: Ed. da Unicamp, 2004.

MACHADO, A. M. N. Universidades comunitárias: um modelo brasileiro para interiorizar a educação superior. In: SCHMIDT, J. P. (Org.). Instituições comunitárias: instituições públicas não-estatais. Santa Cruz do Sul: EDUNISC, 2009.

MIN - Ministério da Integração Nacional. Bases para uma proposta de desenvolvimento e integração da Faixa de Fronteira. Grupo de Trabalho Interfederativo de Integração Interfronteiriça. Ministério da Integração Nacional, Brasília, DF: MI 2010. Disponível em: <http:/ / www.integracao. gov.br/web/guest/comissao-permanente-para-o-desenvolvimento-ea-integracao-da-faixa-de-fronteira>. Acesso em: 1 jul. 2014.

MUNIZ, M. D. Educação superior em Santa Catarina: consolidação e expansão. 2006. Tese (Doutorado em Engenharia de Produção)Universidade Federal de Santa Catarina, Santa Catarina, 2006.

PEGORARO, L. O terceiro setor e o ensino superior no Brasil: o sistema fundacional catarinense. In: PERONI, V. M. V.; BAZZO, V. L.; PEGORARO, L. (Orgs.). Dilemas da educação brasileira em tempos de globalização neoliberal: entre o público e o privado. Porto Alegre: UFRGS, 2006.

Terceiro setor na educação superior brasileira. Campinas: Leitura Crítica, 2013.

RADIN, J. C. Representações da colonização. Chapecó: Argos, 2009.

RENK, A. A luta da erva: um ofício étnico da nação brasileira no oeste catarinense. 2. ed. Chapecó: Argos, 2006. 
Sociodicéia às avessas. Chapecó: Argos, 2000.

SAMPAIO, H. O ensino superior no Brasil: o setor privado. São Paulo: Hucitec, 2000.

SANTOS, M. O lugar e o cotidiano. In: SANTOS, B. de S.; MENEZES, M. P. (Org.). Epistemologias do Sul. São Paulo: Cortez, 2010.

SAVIANI, D. O legado educacional do "longo século XX" brasileiro. In: SAVIANI, D. et al. (Org.). Legado educacional do século $\mathbf{X X}$ no Brasil. Campinas: Autores Associados, 2004.

História das ideias pedagógicas no Brasil. Campinas: Autores Associados, 2007.

SILVA JÚNIOR, J. R.; SGUISSARDI, V. Novas faces da educação superior no Brasil: reforma do Estado e mudanças na produção. 2. ed. São Paulo: Cortez/UFS-IFAN, 2001.

SOUSA SANTOS, B. de. A crítica da razão indolente: contra o desperdício da experiência. 4. ed. São Paulo: Cortez, 2002.

A universidade no século XXI: para uma reforma democrática e emancipatória da Universidade. 2. ed. São Paulo: Cortez, 2005.

TREVISOL, J. V.; CORDEIRO, M. H.; HASS, M. Construindo agendas e definindo rumos. Chapecó: Edições UFFS, 2011.

TREVISOL, J. V.; LÓ, M. (Orgs.). Educação e política. Movimentos sociais e participação no processo de criação da UFFS. Chapecó: UFFS, 2015 (formato DVD).

TREVISOL, J. V. Movimentos sociais e universidade popular no Brasil: a experiência de implantação da Universidade Federal da Fronteira Sul. In: ALMEIDA, M. de L. P. de; CATANI, A. M. (Org.). Educação Superior Iberoamericana: uma análise para além das perspectivas mercadológicas da produção de conhecimento. Buenos Aires: CLACSO, 2015a. Disponível em: <www.clacso.org>. Acesso em: 10 jun. 2015. 
. O ensino superior público na Mesorregião Fronteira Sul: a implantação da UFFS. In: RADIN, J. C.; VALENTINI, D.; ZARTH, P. A. (Org.). História da Fronteira Sul. Porto Alegre: Letra \&Vida, 2015b.

Políticas e processos do ensino superior em Santa Catarina: análise dos indicadores do INEP da região Oeste (1991-2004). In: SOPELSA, O.; TREVISOL, J. V. (Org.). Currículo, diversidade e políticas públicas. Joaçaba: Ed. Unoesc, 2009.

TURMENA, L. Educação superior e política educacional: a gênese do ensino superior no sudoeste do estado do Paraná. Revista HISTEDBR [On-line], Campinas, n. 44, p. 189-201, dez. 2011.

UFFS - Universidade Federal da Fronteira Sul. Princípios norteadores do Projeto Político Institucional da UFFS. 2009. Disponível em: <www. uffs.edu.br>. Acesso em: 12 jun. 2015.

. Documento Final da I Conferência de Ensino, Pesquisa e Extensão. In: TREVISOL, J. V.; CORDEIRO, M. H.; HASS, M. Construindo agendas e definindo rumos. Chapecó: Edições UFFS, 2011.

Portal institucional. Disponível em: <www.uffs.edu.br>. Acesso em: 1 jul. 2014.

VALENTINI, D. J. Atividades da Brazil Railway Company no sul do Brasil: a instalação da Lumber e a Guerra do Contestado. 2009. Tese (Doutorado em História) - Pontifícia Universidade Católica do Rio Grande do Sul, Porto Alegre, 2009. 